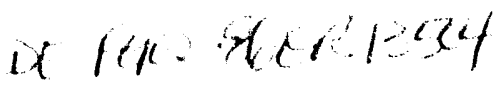

\title{
PHOTOINDUCED ELECTRON TRANSFER PROCESSES IN HOMOGENEOUS AND MICROHETEROGENEOUS SOLUTIONS
}

Progress Report

for Period 4/16/92 - 12/1/92

David G. Whitten

University of Rochester

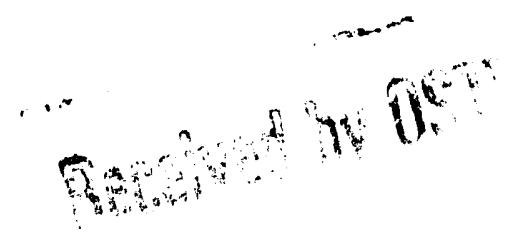

Rochester, New York 14627

December 1992

Prepared for

THE U.S. DEPARTMENT OF ENERGY

AGREEMENT NO. DE-FG02--86ER 13504

MASTER DISTRIBUTION OF THIS DOCUMENT IS UNLIMTEED

\section{DISCLAIMER}

This report was prepared as an account of work sponsored by an agency of the United States Government. Neither the United States Government nor any agency thereof, nor any of their employees, makes any warranty, express or implied, or assumes any legal liability or responsibility for the accuracy, completeness, or usefulness of any information, apparatus, product, or process disclosed, or represents that its use would not infringe privately owned rights. Reference herein to any specific commercial product, process, or service by trade name, trademark, manufacturer, or otherwise does not necessarily constitute or imply its endorsement, recommendation, or favoring by the United States Government or any agency thereof. The views and inions of authors expressed herein do not necessarily state or reflect those of the Unitw States Government or any agency thereof. 


\section{REPORT OF TECHNICAL PROGRESS}

$$
4 / 16 / 92 \text { to } 12 / 1 / 92
$$

\section{Progress in the past year.}

Our studies during the past year have focused on rapid and efficient bond-fragmentation reactions initiated through photoinduced electron transfer. We have made progress in each of the areas outlined in the renewal proposal of October 1991 and the work will be described following the outline of work proposed in that document.

We have examined the electron transfer induced fragmentation of a number of donors, especially 1,2 diamines and closely related compounds. Our studies with the diamines have focused on the reactivity of the three amines shown below, 1-3. We have found that

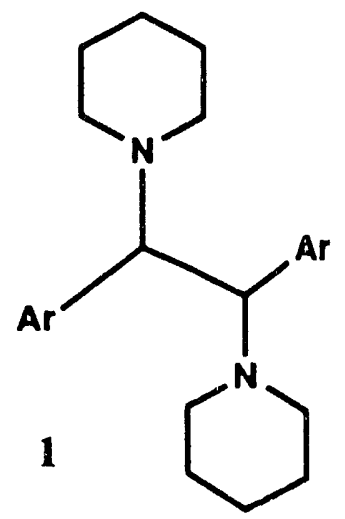

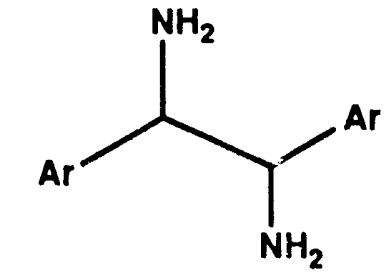

2

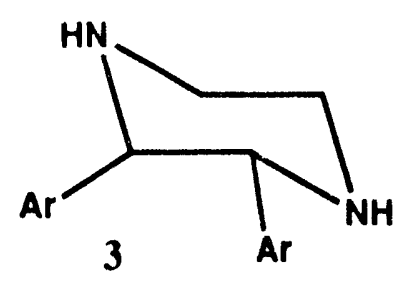

amines 1 and 2 fragment with rate constants in the range $3 \times 10^{8}-2 \times 10^{9} \mathrm{M}^{-1} \mathrm{sec}^{-1}$. The structurally rigid amine 3 also fragments fairly rapidly and we are presently measuring the rate and efficiency with several acceptors in a number of different solvents. One of the more interesting finding with these and other amines is that the quantum efficiencies generally increase with a lowering of temperature. Preliminary findings indicate this is due to activation parameters which indicate a very small enthalpy of activation but a relatively moderate negative entropy of activation. We have developed correlation diagrams which suggest the negative entropy of activation can be associated with the constrained transition state in the cation radical leading to the two incipient iminium systems which result from fragmentation. 
We have also examined a series of amino-substituted pinacols and related compounds which undergo similar but slower fragmentation processes when converted to their cation radicals by photoinduced electron transfer. Here again we obtain activation parameters suggesting an entropic limitation to fragmentation rates which may be a general feature of cation radical bond cleavage processes.

Our studies with linked and polymeric electron donor-electron acceptor coupled molecules have also progressed well. We have studied linked molecule 4 and are currently preparing compound 5. We find that 4 undergoes very efficient fragmentation in a variety of solvents and gives cleanly<smiles>N#Cc1c2ccccc2c(C#N)c2cc(C(=O)Oc3ccc(C(C(c4ccccc4)N4CCOCC4)N4CCOCC4)cc3)ccc12</smiles>

the products expected from intermolecular reaction. We have also prepared several polymers containing diamine repeat units and anthraquinone or nitroaromatic acceptors that can be photoactivated by visible irradiation. We find that these polymers fragment efficiently in solution and apparently photodegrade even in the solid state. The latter finding is especially significant and indicates that electron transfer fragmentations may be expected to be an important reaction even under conditions where no solvent participation can occur. 
In other studies we have continued . - t nearly completed for the present time our investigations of the singlet oxygen initiated fragmentation reactions of diamines, amino alcohols and aminoketones. We have recently turned our attention to the investigation of some fragmentable electron acceptors such as p-cyanobenzyl bromide. Our preliminary experiments indicate that irradiation of electron donors such as methyl-or methoxy-naphthalenes can initiate efficient fragmentation of the electron deficient bromide. We are currently measuring the rate of the fragmentation reaction which occurs on at least the nanosecond time scale.

\section{Publications.}

C. A. Chesta and D. G. Whitten, "Photocyclization of $\alpha$-Keto Amides in Homogeneous Solution and Aqueous Cyclodextrin Media. The Role of Zwitterions and Diradicals in Photoinduced Electron Transfer Reactions," J. Am. Chem. Soc., 1992, 114, 2188.

H. Gan, X. Zhao, D. G. Whitten, "Amine Photoredox Reactions: A Photoinduced "Methylene Shuttle" Initiated via Two-Electron Oxidation of a Tertiary Amine by Anthraquinone," $J$. Am. Chem. Soc., 1991, 113, 9409.

W. R. Bergmark, C. DeWan, D. G. Whitten, "Unusual Redox Behavior in the Photoinduced Electron Transfer Reactions of Amino Ketones," J. Am. Chem. Soc., 1992, 114, 8810.

C. M. Haugen, W. R. Bergmark, D. G. Whitten, "Singlet Oxygen Mediated Fragmentation of Amino Alcohols, 1,2 Diamines and Amino Ketones," J. Am. Chem. Soc., in press.

J. W. Leon and D. G. Whitten, "Efficient Photofragmentation of a Linked Donor-Acceptor System. Anthraquinone-Induced SET Cleavage of a 1,2-Diamine," J. Am. Chem. Soc., submitted.

D. G. Whitten, M. A. Kellett, J. Leon and H. Gan, "Photoinduced Electron Transfer Reactions: Factors Controlling the Rate and Efficiency of C-C Bond Cleavage in Cation Radicals," Proceedings International Conference on Storage and Conversion of Solar Energy, submitted. 

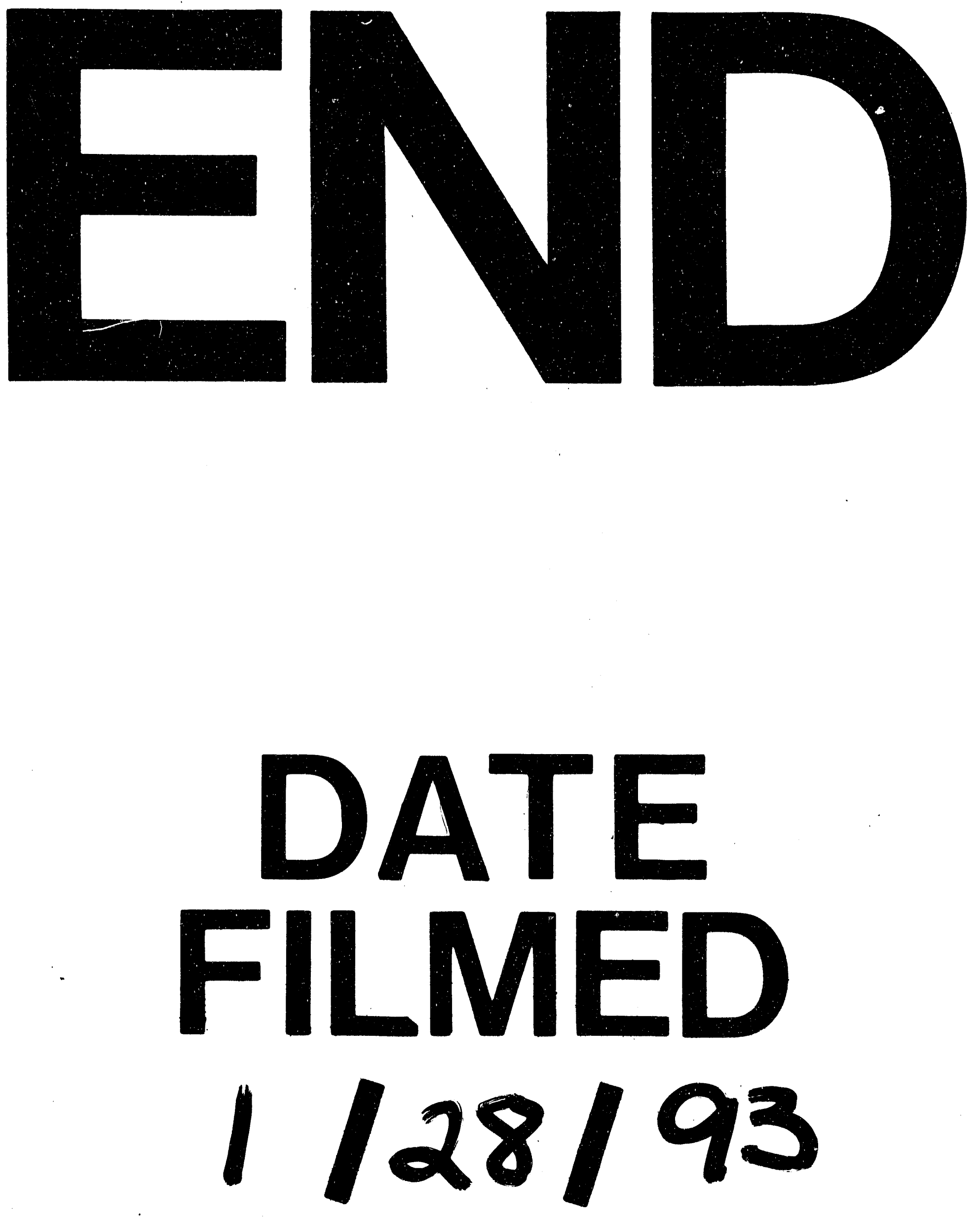
